\title{
Oligomeric proanthocyanidins from grape seeds effectively inhibit ultraviolet-induced melanogenesis of human melanocytes in vitro
}

\author{
SHAO-XIA ZI ${ }^{1,2 *}$, HUI-JUN MA ${ }^{2 *}$, YOU LI ${ }^{2}$, WEN LIU ${ }^{2}$, QING-QI YANG ${ }^{2}$, GUANG ZHAO $^{2}$ and SHI LIAN ${ }^{1}$ \\ ${ }^{1}$ Department of Dermatology, Xuan Wu Hospital, Capital Medical University, Beijing 100053; ${ }^{2}$ Department of \\ Dermatology, The Airforce General Hospital of the Chinese People's Liberation Army, Beijing 100036, P.R. China
}

Received September 23, 2008; Accepted October 21, 2008

DOI: 10.3892/ijmm_00000117

\begin{abstract}
The oligomeric proanthocyanidins (OPCs) from grape seeds are expected to be novel and potent anti-oxidants that more effectively protect skin cells against oxidative stress. UV-induced oxidative stress is considered to promote melanogenesis and serious skin damage. However, the effect of OPCs on UV-induced melanogenesis is still unknown. To investigate the role of OPCs on mleanogenesis of human melanocytes with UV exposure, we evaluated the effects of melanogenesis, cellular cycle, intracellular reactive oxidative species (ROS) level and protein level of melanogenic enzyme in cultured human melanocytes following UV-irradiation by OPCs. After treatment with different doses of OPCs or L-ascorbic acid, normal human melanocytes (NHM) were irradiated by $15 \mathrm{~mJ} / \mathrm{cm}^{2} \mathrm{UV}$ light. Then, cellular melanin content, activity of tyrosinase were examined. Moreover, the protein analysis of tyrosinase, tyrosinase related protein 1 (TRP1), and tyrosinase related protein 2 (TRP2) were observed by Western blotting. Levels of UV-induced ROS in melanocytes and the responses of cell cycle were also examined by immunofluorescence techniques. This study demonstrated that OPCs, significantly inhibited the cell dead induced by UV irradiation in a dose-dependent manner and OPCs alone, has no effects on melanogenesis of NHM, however, it significantly inhibited UV-induced melanogenesis in a dose-dependent manner. The UV-induced intracellular ROS enhancement
\end{abstract}

Correspondence to: Dr Shi Lian, Department of Dermatology, Xuan Wu Hospital, Capital Medical University, Changchun Street 45, Xuanwu District, Beijing 100053, P.R. China

E-mail: toyangcl@yahoo.com.cn or

Dr Hui-Jun Ma, Department of Dermatology, The Airforce General Hospital of Chinese PLA, Fucheng Road 30, Haidian District, Beijing 100036, P.R. China

E-mail: melanocytes@163.com

${ }^{*}$ Contributed equally

Key words: melanogenesis, proanthocyanidins, melanocytes, UV light, photo-protection, reactive oxidative species, cell cycle was also prevented by addition of OPCs in a dose-dependent manner. Meanwhile, OPCs also inhibited the extent of G1 arrest that was induced by UV exposure. OPCs can decrease the protein level of tyrosinase, TRP1 and TRP2 in UVirradiated NHM. Thus, OPCs have potential effects of photoprotection on human melanocytes by improving cell viability, scavenging intracellular ROS, adjusting cell cycle and inhibiting protein expression of melanogenic enzymes.

\section{Introduction}

Melanin plays an important protective role against ultraviolet irradiation, but overproduction and accumulation of melanin could create serious skin problems such as freckles, age pigment, and melasma. Thus, the inhibition of melanogenesis has been the focus on medicinal and cosmetic treatments for skin depigmenting and lightening. Ultraviolet (UV) radiation can increase the melanization and the proliferation of melanocytes by acting on melanocytes directly $(1,2)$ or indirectly through the release of keratinocyte derived factors (3). UV radiation also induces the formation of reactive oxygen species (ROS) in the skin; these ROS assist melanin biosynthesis and damage DNA, and then may induce the proliferation and/or apoptosis of melanocytes (4-6). $\mathrm{H}_{2} \mathrm{O}_{2}$, which is one of the ROS generated, causes an increase in the level of tyrosinase mRNA (7). The dose of UV irradiation seems to regulate and control the UV-induced proliferation of melanocytes. Quevedo et al (8) reported that UV radiation induced proliferation and melanogenesis of melanocytes was reduced by the topical application of antioxidants such as vitamins $\mathrm{C}$ and $\mathrm{E}$ to the skin of hairless mice. UV irradiation induced $8-\mathrm{OHdG}$ (a representative DNA base-modified product generated by ROS) within DNA of cultured mouse keratinocytes (9), and also induced the proliferation of keratinocytes in human skin (10). Therefore, ROS are considered to play important roles in regulating the proliferation of melanocytes as well as keratinocytes and melanogenesis of melanocytes, while ROS scavengers and inhibitors of ROS production, such as antioxidants, may reduce hyperpigmentation or prevent new UV-induced melanogenesis.

Proanthocyanidins, which are oligomers and polymers of polyhydroxy flavan-3-ol units, such as (+)-catechin and (-)-epicatechin (11), are present in large amounts in the 
polyphenols of red wine and grape seeds $(12,13)$. In grape seed extract (GSE), only the procyanidin-type of proanthocyanidins has been detected (14). GSE is known as a powerful antioxidant that protects the body from premature aging, disease, and decay. Dietary supplements such as GSE enriched in OPCs have been suggested to have multiple health benefits, due to antioxidant and other beneficial activities of the plant extract (15-19). GSE provides excellent protection against oxidative stress and free radical-mediated tissue injury (20). It has been reported that antioxidants or compounds with redox properties can inhibit or delay hyperpigmentation (21). Topical application of GSE enhances sun protection factor in human volunteers (20). It has been reported that proanthocyanidin from GSE inhibited the activity of tyrosinases obtained from mushroom and from B16 mouse melanoma cells and decreased the melanin content of the cells (22). Yamakoshi et al (23) demonstrated that oral administration of GSE has been effective in lightening the UV-induced pigmentation of guinea pig skin. This effect may be related to the inhibition of melanin synthesis by tyrosinase in melanocytes and the ROS-related proliferation of melanocytes. Such evidence strongly suggests that proanthocyanidin-rich GSE improves hyperpigmentation of the skin in animal models, however, little is known of such effect in cultured human melanocytes.

In this study, we examined the inhibitory effects of OPCs from GSE on UV-induced melanogenesis in human melanocytes. Furthermore, we also investigated the effects of OPCs on cell cycle, intracellular ROS level and protein level of melanogenic enzymes of NHM following exposure UV light and discussed the molecular basis of photo-protection of OPCs from GSE against UV irradiation.

\section{Materials and methods}

Antibodies and reagents. Grape seed OPCs were donated by Lan Ke Biotech Co., Ltd. (Changchun, Jilin Province, P.R. China). According to the manufacturer, this OPC extract contained essentially dimeric $(17.4 \%)$, trimeric $(16.3 \%)$, tetrameric $(13.3 \%)$ and oligomeric (5-13 Units) proanthocyanidins $(53.0 \%)$. The $\alpha$ PEP7h, $\alpha$ PEP1h and $\alpha$ PEP8h polyclonal rabbit antibodies generously supplied by Professor V.J. Hearing (NCI-NIH, Bethesda, MD, USA). 6-caboxy-2', 7'-dichlorodihydro-fluorescein diacetate (CDCFH) was purchased from Molecular Probes Inc. (Eugene, OR, USA). Bio-Rad protein assay kit was supplied by Bio-Rad Lab. (Hercules, CA, USA). Fetal bovine serum (FBS) was purchased from Invitrogen Corporation (Grand Island, NY, USA). Trypsin-EDTA, penicillin, and streptomycin were obtained from Gibco Invitrogen Co., Ltd. (Carlsbad, CA, USA). Thiazolyl blue (MTT) was from Ameresco, Inc. (Solon, $\mathrm{OH}$, USA). Unless stated otherwise, other reagents were purchased from Sigma-Aldrich, Inc. (St. Louis, MO, USA).

Cell culture of NHM. Normal human melanocytes (NHM) were obtained from juvenile foreskin tissue (skin type III/IV). Foreskins were kindly supplied by the Airforce General Hospital (Beijing, P.R. China) with the informed consent of donors. Ethical approval for the use of this tissue was obtained from the Airforce General Hospital local research ethics committee. Primary NHM were cultured as before (24). To isolate the melanocytes, foreskin was freed from connective tissue, cut into small pieces and incubated overnight in Hanks' balanced salt solution (HBSS) (Invitrogen Corporation) containing $5 \mathrm{mg} / \mathrm{ml}$ dispase (Roche Diagnostics, Lewes, UK). The epidermis was then separated from the dermis and incubated at $37^{\circ} \mathrm{C}$ in a trypsin solution for 15-30 min with gentle agitation. Digestion was halted by the addition of $5 \%$ FBS, and harvested cells were maintained in MCDB153 medium supplemented with $5 \% \mathrm{FBS}, 5 \mathrm{ng} / \mathrm{ml} \mathrm{bFGF,} 10 \mathrm{ng} / \mathrm{ml}$ NGF- 3,5 nM ET-1, $50 \mu \mathrm{g} / \mathrm{ml}$ gentamicin, $100 \mathrm{U} / \mathrm{ml}$ penicillin, $100 \mu \mathrm{g} / \mathrm{ml}$ streptomycin. Cells were cultured in a humidified atmosphere containing $5 \% \mathrm{CO}_{2}$ in air at $37^{\circ} \mathrm{C}$. Melanocytes were cultured in $25-\mathrm{cm}$ plastic flasks (Corning Incorporated Life Sciences, Acton, MA, USA) and chosen the third or the fourth passage for each assay. All the experiments were performed in triplicate and repeated 3 times to ensure reproducibility.

Irridiation of melanocytes with UV light. Before exposure to UV light, the culture medium in each dish was removed and each dish was incubated with $200 \mu 1$ phosphate buffered saline (PBS) containing no fullerene. Melanocytes were irradiated with multiport solar simulators (Ao-Hua Co, Beijing, P.R. China). Immediately after irradiation, PBS was replaced with fresh culture medium. The control samples were kept in the dark under the same conditions. This sun simulator included a $450 \mathrm{~W}$ xenon lamp and a dichroic mirror. Radiation was filtered with a WG 320,1-mm-thick short cut-off filter, plus a UG 11, 1-mm-thick long cutoff filter (Schott, Clichy, France) to deliver a continuous UV spectrum from 290 to $400 \mathrm{~nm}$. The irradiances were monitored with a calibrated SUN5 digital spectroradiometer (National Institute of Measuring, Beijing, P.R. China).

Determination of cell viability. Cell viability was measured by the MTT assay. To assess the sensitivity of NHM to UV exposure, NHM were seeded at $5 \times 10^{4}$ cells/well in 96-well plates and treated with a range of doses of $\operatorname{UV}(5,10,15,30$, $50,70,100 \mathrm{~mJ} / \mathrm{cm}^{2}$ ). Immediately after irradiation, PBS was replaced with fresh culture medium. Then MTT reagent was added to each well $24 \mathrm{~h}$ after UV exposure and cells were incubated for an additional $4 \mathrm{~h}$ at $37^{\circ} \mathrm{C}$. Solubilization solution ( $10 \%$ sodium dodecyl sulfate in $0.01 \mathrm{M} \mathrm{HCl}$, Roche Applied Science) was then added for a further incubation of $18 \mathrm{~h}$ at $37^{\circ} \mathrm{C}$. Absorbance at $570 \mathrm{~nm}$ was detected using a Bio-Rad 550 microplate reader (Bio-Rad Laboratories Inc.). The highest dose with the cell survival rate $>75 \%$ was chosen for further study.

To determined the viability of NHM under OPCs exposure, OPCs diluted in culture medium $(5,25,50,250,500,1000 \mu \mathrm{g} /$ $\mathrm{ml}$ ) were used to treat cells for $48 \mathrm{~h}$. After incubated with MTT for $4 \mathrm{~h}$, the optical density of each well was read at $490 \mathrm{~nm}$ using a microplate reader.

Measurement of melanin content. Melanin content was measured using a modification of a previously reported method (25). Cells $\left(\sim 10^{7}\right)$ were pelleted by centrifugation at $1,000 \times \mathrm{g}$ for $5 \mathrm{~min}$ and then washed twice with PBS. After further centrifugation, the supernatant was decanted, the 
precipitated cells were resuspended in $200 \mathrm{ml}$ of distilled water, and $1 \mathrm{ml}$ of ethanol-ether 1:1 ( $\mathrm{vol} / \mathrm{vol})$ was added to remove opaque substances other than melanin. This mixture was stored and suspended at room temperature for $15 \mathrm{~min}$. After further centrifugation (3,000 x $\mathrm{g}$ for $5 \mathrm{~min})$, the precipitate was solubilized by treatment with $1 \mathrm{ml}$ of $1 \mathrm{~N} \mathrm{NaOH} / 10 \%$ dimethyl sulfoxide at $80^{\circ} \mathrm{C}$ for $30 \mathrm{~min}$ in a capped test-tube. The absorbance was measured at $470 \mathrm{~nm}$, and the melanin content per cell was calculated and expressed as a percentage of control $(=100 \%)$.

Assay of cellular tyrosinase activity. Cellular tyrosinase activity was assayed as DOPA oxidase activity using a modified version of a previously reported method $(26)$. Cells $\left(\sim 10^{7}\right)$ were pelleted and then washed twice with PBS. After centrifugation, the supernatant was decanted. The cell pellet was dissolved in $1.0 \mathrm{ml}$ of $0.5 \%$ sodium deoxycholate in distilled water and allowed to stand at $0^{\circ} \mathrm{C}$ for $15 \mathrm{~min}$. Tyrosinase activity was analyzed spectrophotometrically by following the oxidation of DOPA to DOPAchrome at $475 \mathrm{~nm}$. The reaction mixture, consisting of $3 \mathrm{ml}$ of $0.1 \%$ L-DOPA in $0.1 \mathrm{M}$ PBS (pH 6.8), was mixed with the cell lysate (the reaction mixture was freshly prepared every $2 \mathrm{~h}$ ). Assays were performed at $37^{\circ} \mathrm{C}$ in a spectrophotometer. The rate was measured during the first $10 \mathrm{~min}$ of the reaction while it was linear. Corrections for auto-oxidation of L-DOPA in controls were made. Specific activity was defined as the amount of DOPAchrome formed (absorbance at $475 \mathrm{~nm}$ ) per $10 \mathrm{~min}$ per cell, and is expressed as a percentage of control $(=100 \%)$.

Measurement of intracellular ROS level. In order to investigate the influence of OPCs on the ROS level in melanocytes, we used $\mathrm{CDCFH}$ as a redox indicator and used fluorometry as a detection system. The CDCFH-DA dye was taken up by cells, esterolyzed to be membrane-impermeable $\mathrm{CDCFH}$, and oxidized to be highly fluorescent CDCF by reaction with ROS such as hydroperoxide and hydrogen peroxide $(27,28)$. The cultures were rinsed with $\mathrm{PBS}(-)$ and incubated in phenol red-free MCDB153 medium containing $7 \mu \mathrm{M}$ CDCFH-DA for $30 \mathrm{~min}$. The fluorescence intensity of the oxidative form of $\mathrm{CDCFH}$ was measured at $525 \mathrm{~nm}$ of an emission wavelength after excitation at $488 \mathrm{~nm}$ with a fluorescence plate reader CytoFluor 2350 (Millipore Corp., Bedford, MA, USA). The methanol-killed cells were treated as the blank ones. Then cells were trypsinized and daubed on the slide glass. Coverslips were rinsed with PBS, mounted in glycerol, and viewed with fluorescence microscopy (Nikon Eclipse E 600, Nikon Co.).

Cell cycle analysis. Melanocytes were plated in 100-mm dishes at a density of $5 \times 10^{5}$ cells. Three days later, cells were irradiated with $15 \mathrm{~mJ} / \mathrm{cm}^{2}$ of UV light. After the irradiation, dishes was supplied with culture medium containing different concentrations $(0,10,50,100 \mu \mathrm{g} / \mathrm{ml})$ of OPCs for incubation. At the end of the incubation period, cells were harvested, fixed, denatured, and washed in PBS twice, resuspended in PBS and treated with $0.5 \mathrm{mg} / \mathrm{ml}$ RNase A $100 \mu \mathrm{l}$ for half an hour at $37^{\circ} \mathrm{C}$. Then $1 \mathrm{mg} / \mathrm{ml}$ propidium iodide (PI) $100 \mu \mathrm{l}$ was added and incubated for $20 \mathrm{~min}$ in dark place. Cells were analyzed by flow cytometry using an EPICS 753 flow cytometer (Coulter Electronics, Hialeah, FL, USA). PI was excited with the 488-nm line of an argon ion laser. Fluorescence emission for PI was detected selectively by collecting $575 \pm 12.5 \mathrm{~nm}$. When analyzing PI, gates were also set on the peak versus integral PI signals to eliminate doublets. The PI signals were analyzed using Multicycle (Phoenix Software, San Diego, CA, USA). Data were acquired using BD CellQuest software, and cell cycle profiles were analysed using ModFit LT (Verity Software House, Topsham, ME, USA) software to determine relative proportions of cells in each cell cycle compartment.

Western blot analysis of tyrosinase, TRP1, and TRP2. To identify the amount of tyrosinase, TRP1, and TRP2, Western blotting was performed (24). At least $1 \times 10^{6}$ melanocytes were harvested, pelleted, washed with PBS, and lysed. An equal amount of protein $(5-8 \mu \mathrm{g})$ from cell lysates was loaded onto each lane and electrophoresed on $7.5 \%$ SDS-polyacrylamide gels using a minigel apparatus. Proteins in the gels were transferred to polyvinylidene difluoride membranes (Millipore Corp.). Protein contents were measured using the Bio-Rad protein assay kit with BSA as a standard. Normal rabbit serum was used as a control. The membranes were blocked with $3 \%$ BSA and incubated with specific peptide antisera (1:500 dilution), anti- $\alpha$ PEP7h, anti- $\alpha$ PEP1h, and anti- $\alpha$ PEP8h antibodies, which recognize the $\mathrm{COOH}$ termini of tyrosinase, TRP1, and TRP2, respectively. After incubation with the above primary antibodies overnight, the lanes were reacted with horseradish peroxidase conjugated goat anti-rabbit antibody (1:500 dilution) for $1 \mathrm{~h}$. The resulting bands were visualized by reacting the membranes with diaminobenzidine (DAB).

Statistical analysis. All data were processed statistically by the software of SPSS 11.0, and are expressed as mean \pm standard deviation of 3 independent experiments. $\mathrm{P}<0.05$ were considered significant and those differences were determined by ANOVA test and appropriate post-hoc tests.

\section{Result}

Effects of UV and OPCs on viability and cell growth. To determine a suitable dose of UV ray and to explore the putative cytotoxicity of OPCs, we evaluated the viability of NHM in the presence and absence of UV and OPCs using MTT assay. A dose of $\geq 50 \mathrm{~mJ} / \mathrm{cm}^{2} \mathrm{UV}$ caused $\sim 60 \%$ cell death, the $\mathrm{IC}_{75}$ value (the $75 \%$ maximal inhibitory concentration) is $15 \mathrm{~mJ} / \mathrm{cm}^{2}$ (Fig. 1A). Then we chose the dose of UV for the next experiments. OPCs caused no significant change in cell viability at final concentrations of $5-250 \mu \mathrm{g} / \mathrm{ml}$. At the highest concentration of $1000 \mu \mathrm{g} / \mathrm{ml}$, OPCs only reduce $21 \%$ cell viability (Fig. 1A). In UV-irradiation group, OPCs significantly improved the cell viability in a dose-dependent manner (Fig. 1B). These results indicated that OPCs has a long range of non-cytotoxic concentrations on NHM and have potential photo-protective efficacy.

Inhibitory effects of OPCs on melanin synthesis after $U V$ exposure in NHM. We first investigated the effects of OPCs on melanin content in NHM, but there are no effect on melanin content of NHM which was observed by OPCs (Fig. 2). In UV radiated NHM group, the melanin content in 
A

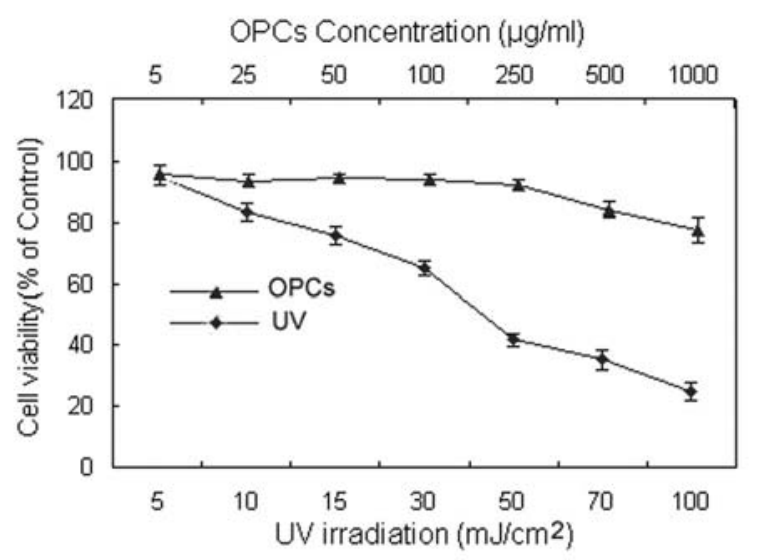

B

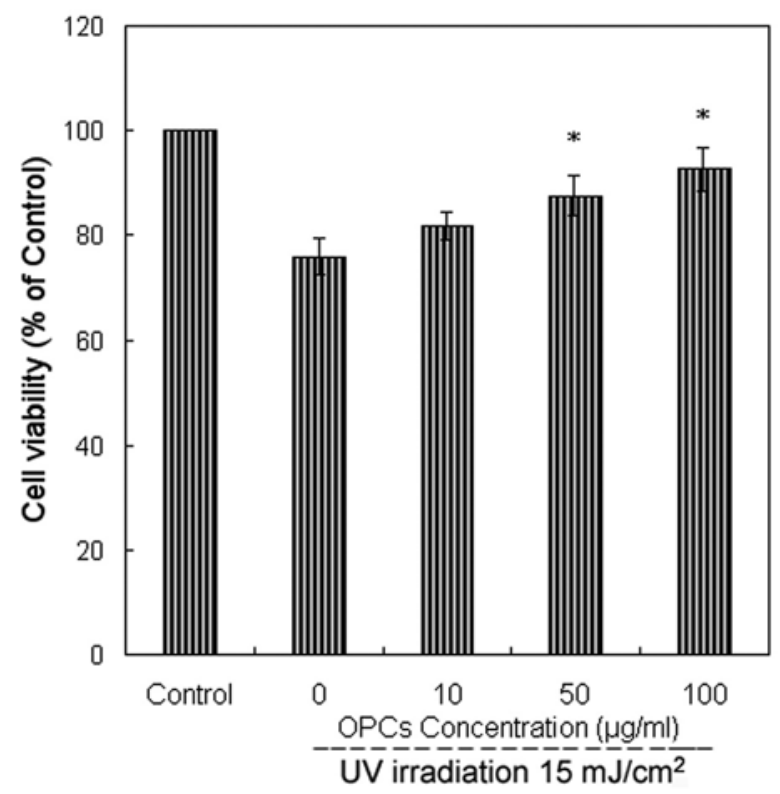

Figure 1. (A) Dose-dependent suppression of NHM proliferation by UV irradiation and no suppression of NHM proliferation by OPCs were indicated by MTT assay. Different dose $\left(0-100 \mathrm{~mJ} / \mathrm{cm}^{2}\right)$ of UV irradiation and various concentration $(0-1000 \mu \mathrm{g} / \mathrm{ml})$ of OPCs was treated with cultured NHM. Data were obtained from three independent experiments and presented as mean $\pm \mathrm{SD}$. $\mathrm{IC}_{75}$ was $15 \mathrm{~mJ} / \mathrm{cm}^{2}$ for $\mathrm{UV}$ irradiation and $1000 \mu \mathrm{g} / \mathrm{ml}$ for OPCs, respectively. (B) Dose-dependent improvement of UV-induced NHM suppression by OPCs was assayed with the MTT method. Data are presented as mean $\pm \mathrm{SD} . \mathrm{n}=4,{ }^{*} \mathrm{P}<0.05$ versus control $\left(0 \mathrm{~mJ} / \mathrm{cm}^{2}\right.$ UV irradiation).

non-pretreated NHM was increased to $180 \%$ versus that in the control cells. Whereas, OPCs significantly reduced UV stimulated melanin production in a dose-dependent manner, and the melanin content in $100 \mu \mathrm{g} / \mathrm{ml} \mathrm{OPCs}$ treated cells was $89.6 \%$ of that in non-pretreated cells. OPCs $(50 \mu \mathrm{g} / \mathrm{ml})$, $10 \mu \mathrm{g} / \mathrm{ml} \mathrm{OPCs}$, and $50 \mu \mathrm{g} / \mathrm{ml} \mathrm{L}$-ascorbic acid reduced the melanin production to $102.4,141.5$ and $136.3 \%$, respectively, of that in non-pretreated cells (Fig. 2). OPCs (50 $\mu \mathrm{g} / \mathrm{ml})$ was more effective than L-ascorbic acid $(50 \mu \mathrm{g} / \mathrm{ml})$.

Inhibitory effects of OPCs on cellular tyrosinase activity in NHM following UV exposure. To investigate the mechanism of inhibition of melanogenesis by OPCs, we further observed

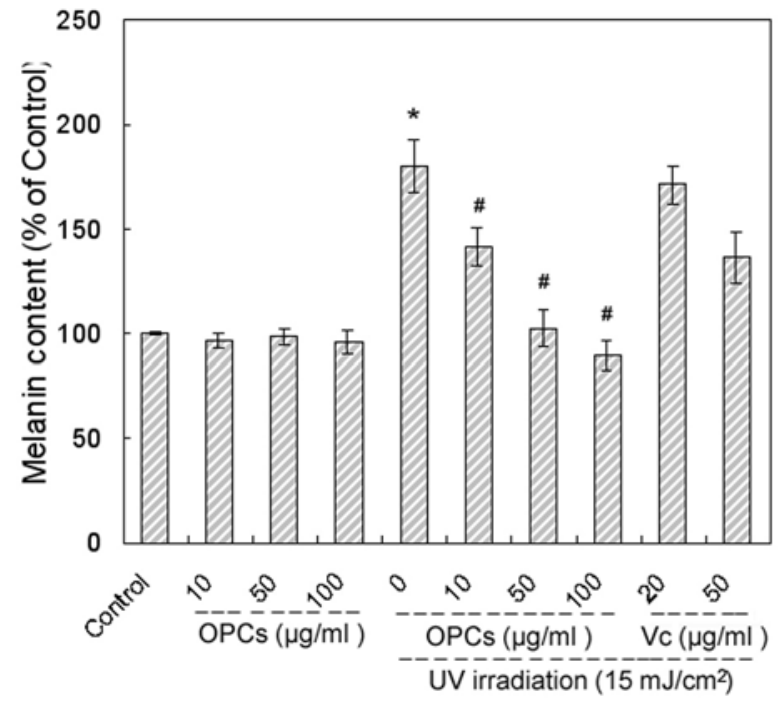

Figure 2. Dose-dependent suppression of NHM cellular melanin content by OPCs in UV irradiated group. NHM were irradiated with $15 \mathrm{~mJ} / \mathrm{cm}^{2} \mathrm{UV}$ light and pre-irradiation administration of multiply concentrations of OPCs $(10,50,100 \mu \mathrm{g} / \mathrm{ml})$ and two doses of vitamin C $(20,50 \mu \mathrm{g} / \mathrm{ml})$. The significant countered reductions of melanin content were observed at 10, 50 and $100 \mu \mathrm{g} / \mathrm{ml}$ of OPCs. However, OPCs alone, at all concentrations investigated did not show any reduction effects. Data are presented as mean \pm SD. $n=4,{ }^{*} \mathrm{P}<0.05$ versus the control, ${ }^{*} \mathrm{P}<0.05$ versus only $\mathrm{UV}$-irradiated group.

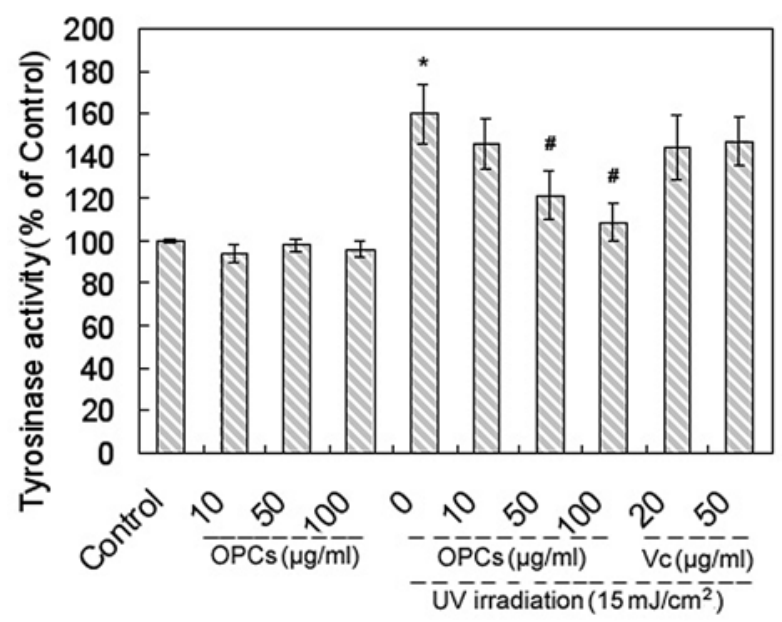

Figure 3. Dose-dependent suppression of NHM intracellular tyrosinase activity by OPCs in UV irradiated group. Tyrosinase activity in NHM after $24 \mathrm{~h}$ of irradiation present or absent OPCs administration was assay. The significant reductions of tyrosinase activity was observed at concentions 10 , 50 , and $100 \mu \mathrm{g} / \mathrm{ml}$ of OPCs. However, OPCs alone, at all concentrations investigated did not show any reduction effects. Data are presented as mean \pm SD. $n=4,{ }^{*} \mathrm{P}<0.05$ versus the control, ${ }^{\#} \mathrm{P}<0.05$ versus only $\mathrm{UV}$-irradiated group.

the effect of OPCs on UV-induced tyrosinase activation and compared with that of L-ascorbic acid in NHM. The results are shown in Fig. 3, UV enhanced cellular tyrosinase activity to a level of $159.3 \%$ higher than the control. However OPCs alone, at all concentrations investigated, did not show any reductive effects than that of the control. In the UV irradiation group, OPCs showed an inhibitory effect on cellular tyrosinase activity in a dose-dependent manner. The tyrosinase activity was suppressed to $108.6 \%$ by OPCs at 100 $\mu \mathrm{g} / \mathrm{ml}, 121.4 \%$ at $50 \mu \mathrm{g} / \mathrm{ml}, 145.2 \%$ at $10 \mu \mathrm{g} / \mathrm{ml}$ and $146.7 \%$ 
A

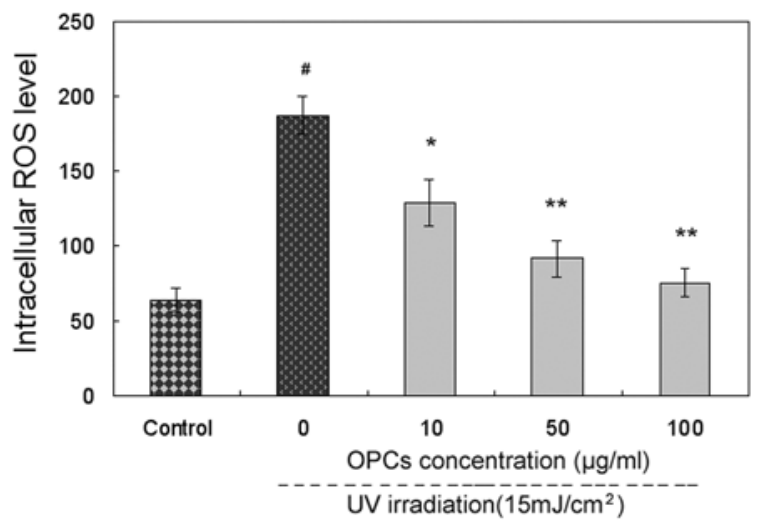

Figure 4. Repressive effects of OPCs on intracellular ROS in UV-irradiated NHM. Human melanocytes were seeded and cultivated for $24 \mathrm{~h}$, and then administered with OPCs at varying concentrations for $48 \mathrm{~h}$. The cells were rinsed and further incubated in phenol red-free MCDB153 containing $7 \mu \mathrm{M}$ CDCFH-DA for $30 \mathrm{~min}$. Then, the cells were irradiated with UV $(15 \mathrm{~mJ} /$ $\mathrm{cm}^{2}$ ). At $1 \mathrm{~h}$ after $\mathrm{UV}$ exposure, the cells were assayed using a fluorescence plate reader (ex $488 \mathrm{~nm}$; em $525 \mathrm{~nm}$ ). (A) The reduction of ROS accumulation of UV-irradiated NHM by OPCs is dose-dependent. Data are expressed as fluorescence intensity value, and each column and bar represent the mean \pm SD of three independent experiments. ${ }^{*} \mathrm{P}<0.05,{ }^{* *} \mathrm{P}<0.01$ as compared with the only UV-irradiated cells. ${ }^{\text {}} \mathrm{P}<0.01$ versus the control. (B) NHM then were trypsinized and daubed on the slide glass and observed using a fluorescence microscope. According to fluorescence intensity being proportional to intracellular ROS amounts, UV radiation induced much more ROS in melanocytes than in both the control cells and pre-OPC-treated melanocytes. Scale bar indicated $20 \mu \mathrm{m}$.

B

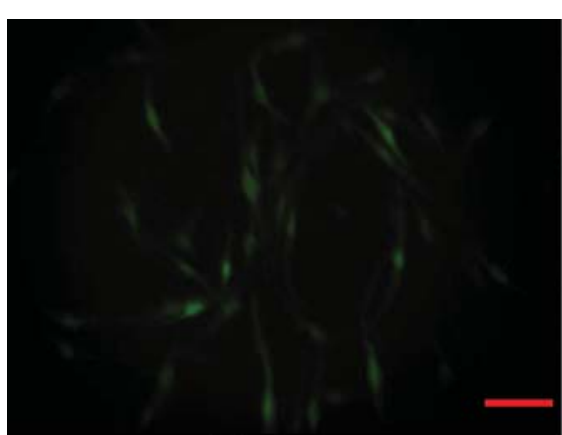

Control

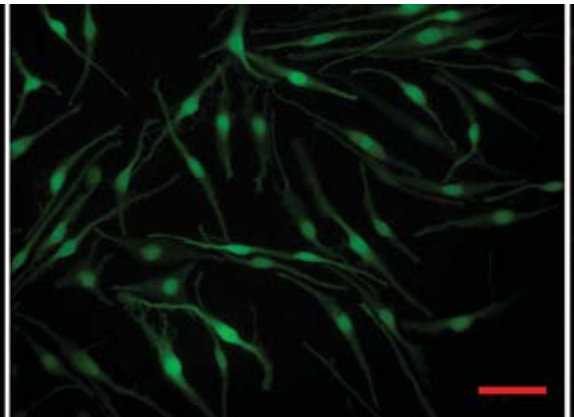

$0 \mu \mathrm{g} / \mathrm{ml}$ OPCs

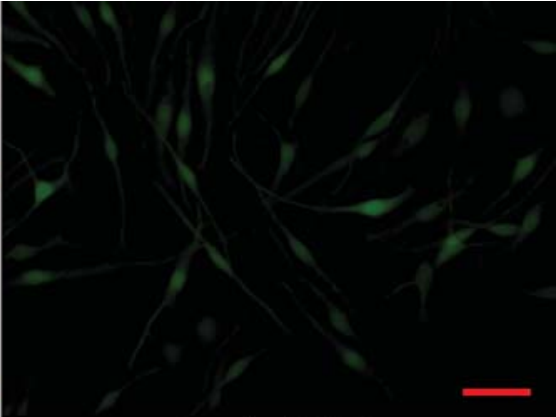

$100 \mu \mathrm{g} / \mathrm{ml}$ OPCs

$15 \mathrm{~mJ} / \mathrm{cm}^{2} \mathrm{UV}$

by L-ascrobic at $50 \mu \mathrm{g} / \mathrm{ml}$ compared with the control. OPCs $(50 \mu \mathrm{g} / \mathrm{ml})$ were more potent than L-ascrobic acid $(50 \mu \mathrm{g} / \mathrm{ml})$.

Scavenging effect of OPCs on UV-enhanced intracellular ROS in NHM. To examine whether OPCs could influence UV-induced elevation of intracellular ROS level in NHM, we quantified the intracellular ROS by CDCFH method as described in Materials and methods. NHM were previously administered with or without different concentrations of OPCs $(10,50,100 \mu \mathrm{g} / \mathrm{ml})$, and then irradiated with UV $(15 \mathrm{~mJ} /$ $\left.\mathrm{cm}^{2}\right)$. The intracellular ROS level detection was performed at $1 \mathrm{~h}$ after UV exposure. As shown in Fig. 4A, at $1 \mathrm{~h}$ after irradiation with UV, significant accumulation of intracellular ROS in non-pretreated cells was observed. In the cells pretreated with OPCs at 10,50 , and $100 \mu \mathrm{g} / \mathrm{ml}$, the ROS level was markedly reduced to 68,48 , and $40 \%$ versus the UVirradiated level, respectively. After UV irradiation, the high fluorescence intensity and morphological abnormalities were observed, whereas OPCs-pretreated cells showed much lower fluorescence intensity (Fig. 4B). The UV-induced intracellular ROS enhancement was prevented by addition of OPCs.

Inhibitory effects of OPCs on growth arrest after $U V$ irradiation. The changes in cell cycle distribution as a function of time after different treatments are shown in Fig. 5. In control group, cells are stimulated to progress through the cell cycle when fresh medium is added immediately following sham exposure (in PBS). This is shown by a sharp drop in the percentage of cells in $\mathrm{G} 1 / \mathrm{G} 0$, as they are stimulated to enter $\mathrm{S}$ phase. There follows a peak in the percentage of cells in
$\mathrm{S}$ phase, which is almost immediately followed by a peak in the percentage in $\mathrm{G} 2 / \mathrm{M}$. By $\sim 60 \mathrm{~h}$ following sham exposure, this wave of proliferation has subsided, and the control cells have returned to their pre-exposure cycling rate, with $\sim 70 \%$ in the $\mathrm{G} 1 / \mathrm{G} 0$ phase of the cell cycle.

In melanocytes exposed to UV irradiation, this increase in transit through the cell cycle is reduced and delayed. The slowing of cells leaving G1/G0 marks the presence of a UVinduced arrest in G1. We used $50 \mu \mathrm{g} / \mathrm{ml}$ OPCs for the experiment and found the G1 arrest effect is inhibited by addition of OPCs, and the strongest effect was observed in cells exposed to UV light. We also demonstrated that the G1 arrest could stop $\sim 50-72 \mathrm{~h}$ after the treatment and the G1 arrest was most obvious at the $24-36 \mathrm{~h}$ after the treatment.

Downregulation of TYR, TRP1, TRP2 expression after $U V$ exposure by OPCs. From results of Western blotting, we found that, in comparison to the control, OPCs $(50 \mu \mathrm{g} / \mathrm{ml})$ did not show any significant effects on expression of tyrosinase, TRP1 and TRP2 in NHM. UV irradiation caused less decrease of the protein level of TRP2 and no effect was observed on the other two enzymes. However, OPCs can decrease the protein level of tyrosinase, TRP1 and TRP2 in UV-irradiated $\left(15 \mathrm{~mJ} / \mathrm{cm}^{2}\right)$ NHM (Fig. 6).

\section{Discussion}

Proanthocyanidins have been reported to exhibit strong antioxidative and free radical scavenging activities in aqueous and $\mathrm{H} 2 \mathrm{O} 2 / \mathrm{NaOH} / \mathrm{DMSO}$ systems (29) and to have an 
A

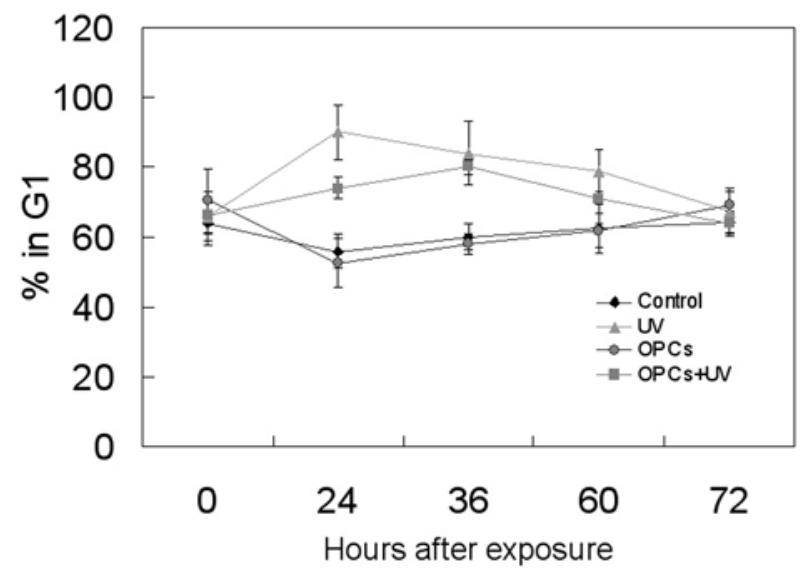

B

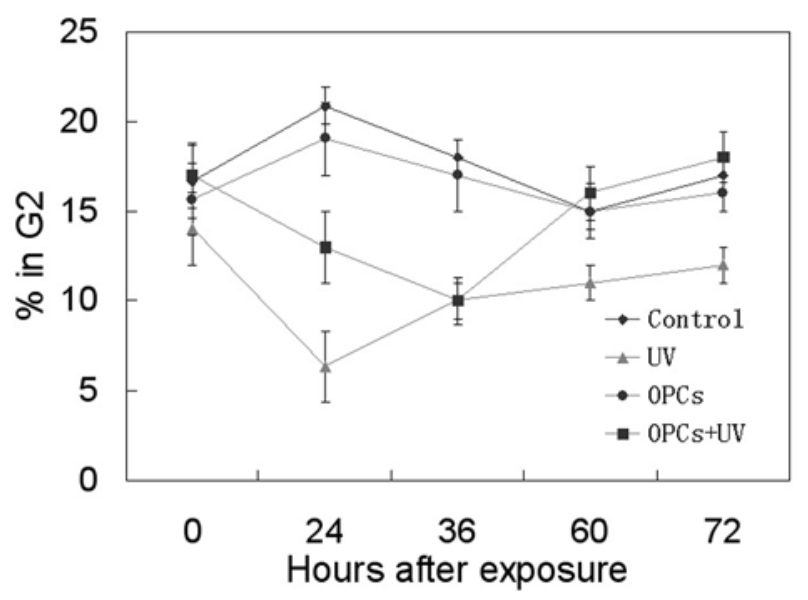

C

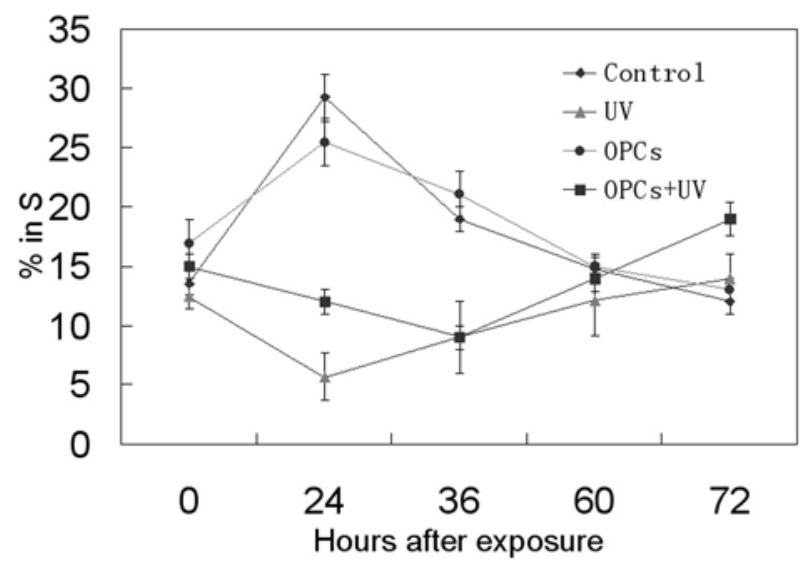

Figure 5. Cell cycle distribution in NHM following exposure to UV radiation. Cells were recovered at intervals from 0 to $72 \mathrm{~h}$ following exposure to UV radiation and DNA content assayed by PI staining and FACS analysis as described in Materials and methods. The points represent mean \pm SD for 2 or 3 independent experiments using NHM from 2 or 3 different donors (all of skin type III/IV). (A) The percentage of cells in G1 phase, (B) the percentage of cells in G2 phase, (C) the percentage of cells in $\mathrm{S}$ phase.

antioxidative activity in rat plasma after oral administration (18). Bagchi et al reported that proanthocyanidin extracted from grape seeds was a stronger free radical scavenger and inhibitor

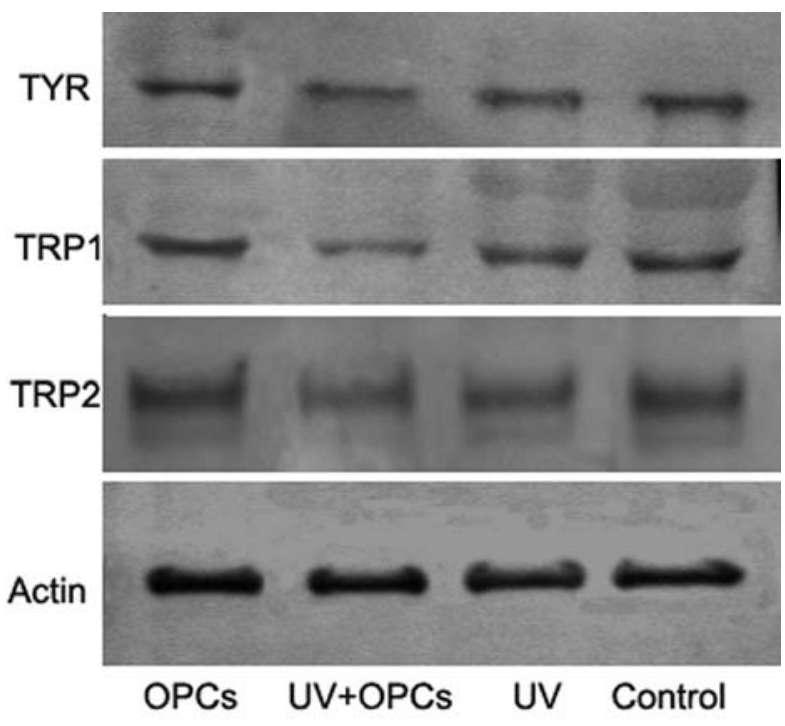

Figure 6. Western blot analysis of tyrosinase, TRP-1 and TRP-2 from cultured NHM after treatment with OPCs $(50 \mu \mathrm{g} / \mathrm{ml})$ or UV-irradiation $\left(15 \mathrm{~mJ} / \mathrm{cm}^{2}\right)$ or OPCs+UV or control. OPCs did not show any significant effects on expression of tyrosinase, TRP1 and TRP2; UV irradiation caused less decrease of the protein level of TRP2. However, OPCs decreased the protein level of the three proteins in UV-irradiated NHM.

of tissue oxidation and DNA damage than vitamin $\mathrm{C}$, vitamin $\mathrm{E}$ succinate, and the combination of vitamin $\mathrm{C}$ and vitamin $\mathrm{E}$ succinate, when they were administered in TPA-treated mice (30). UV radiation can increase the melanization and the proliferation of melanocytes and also induces the formation of free radical, such as ROS and nitrogen oxide (NO), in the skin. These free radical assist melanin biosynthesis and damage DNA and then may induce the proliferation and/or apoptosis of skin cells (4-6). As a powerful antioxidant and free radical scavenger, OPCs may have potent role of photoprotection on melanocytes. It has been shown that OPCs can inhibite the activity of tyrosinases obtained from mushroom and from B16 mouse melanoma cells and decrease the melanin content of the cells (22). Yamakoshi et al (23) also demonstrated the lightening effect on UV-induced pigmentation of guinea pig skin by oral administration of OPCs from GSE. It is therefore plausible that OPCs are of particular role on the UV-induced melanogenesis of NHM.

Yamakoshi et al have observed that the GSE lightening effect was limited to the UV-induced pigmentation and did not have any effect on normal skin in brownish guinea pigs (23). This result implied that melanogenesis and melanocyte proliferation are inhibited in the pigmented skin by GSE, where melanogenic enzymes in melanocytes are relatively active and the melanocytes proliferate. To further understand the role of OPCs from GSE on melanogenisis present or absent with UV irradiation, we detected the cell viability, cellular melanin content, tyrosinase activity of NHM in such above conditions. Pre-irradiation administration of OPCs resulted in significant reduction in UV induced cell killing, clearly establishing its photo-protective efficacy. Our results have shown that UV enhanced cellular tyrosinase activity, but OPCs showed an anti-melanogenic effect in a dose-dependent manner. OPCs not only decreased melanin content but also 
inhibited the cellular tyrosinase activity of UV-treated NHM. These results have demonstrated that OPCs from GSE can reduce the melanogenesis of UV-irradiated group but have no effects on non-UV irradiation group which is consistent with the opinion provided by Yamakoshi et al (23). Then, as an antioxidative agent, OPCs may be used for depigmenting and lightening cosmetic for dark skin.

In mammalian melanocytes, melanogenesis is controlled at least by three regulatory proteins, tyrosinase, and TRP1 and TRP2 (31). In a previous study increasing stimulation of melanogenesis by UV light involved an increase in tyrosinase activity, without any change in the amounts of either tyrosinase or TRP1, but a decrease in the amount of TRP2, as determined by Western blot analysis (24). In our present study, the results of Western blotting also confirmed that protein expression of TRP2 slightly decreased in the UVirradiated cells. However, OPCs have shown no effects on protein expression of the three enzymes as compared to the control. Furthermore, OPCs obviously reduced the protein level of these enzymes from UV-treated NHM. Possibly this can explain why OPCs cannot influence the melanogenisis of non-irradiated NHM, but the irradiated NHM. Thus, the photo-protective properties of OPCs from GSE were first demonstrated in our study.

UV irradiation directly or indirectly results in up-regulation of the genes for these melanogenic enzymes. Several lines of evidence suggest that UV produced ROS and NO are important signals in melanogenesis (32-34). ROS is a collective term for oxygen-derived species, namely oxygen radicals and certain non-radicals that are oxidizing agents and/or easily converted into radicals (35). They exert the pigmentation effects via i) activating keratinocytes and melanocytes to produce above-mentioned melanogenic enzymes, ii) damaging DNA, and/or repairing this damage to transmit the signals of the melanogenesis transduction pathway. Since OPCs is a powerful antioxidative agent, our attention is being concentrated on the effects of neutralization of damaging ROS induced by UV exposure. Our results showed that the reduction of ROS accumulation of UV-irradiated NHM by OPCs is dose-dependent. This study reports, for the first time, the photo-protective potential of OPCs in vitro and we believe that scavenging of UV-induced free radicals appears to be contributing the photo-protective ability.

UV exposure induces cyclobutane pyrimidine dimers and oxidative DNA damage including 8-oxoguanine $(36,37)$, which may contribute to reduced survival. However, UV-induced cytotoxicity is thought to result primarily from non-nuclear oxidative damage to plasma membranes resulting in rapid cell lysis $(38,39)$. Cell cycle responses provide a sensitive indicator of genome-wide damage responses and therefore can be used to monitor the potential for UV irradiation to disrupt DNA metabolism. It has been shown that the DNA damage is repaired by nucleotide excision repair pathways (40). Unrepaired damage is translated into breakage or exchange events during S phase and G2 phase of the cell cycle (40). In addition, the delay in entry of damaged cells into the $S$ phase and block them in G1 phase may have a beneficial effect of providing more time for repair of potential DNA damage before the onset of DNA replication (41). The NHM in the present study exhibited strong G1 block following UV exposure, which suggests that nuclear DNA metabolism may have been affected. OPCs have a similar effect on cell cycle response of NHM as compared to the control, but pre-OPCs treated UV-irradiated NHM showed less content of G1 arrest versus the UV-irradiated NHM. This suggests that OPCs effectively inhibited UV-induced DNA damage and provide indirect evidence for repair of DNA damage.

The present study established that OPCs inhibit UVinduced melanogenesis by attenuating tyrosinase activity, reducing melanin content, and decreasing the protein level of TYP, TRP1 and TRP2 in UV-treated NHM. The photoprotective role of OPCs might be due to diminishing UVcaused intracellular ROS generation and recovering UVinduced G1 arrest.

\section{Acknowledgements}

This study was supported by funds from the National Natural Science Sponsorship of China (30600538). We also thank Dr V.J. Hearing (NCI-NIH, Bethesda, MD, USA) for the generous gift of $\alpha$ PEP1h, $\alpha$ PEP7h and $\alpha$ PEP8h antibodies.

\section{References}

1. Friedmann PS and Gilchrest BA: Ultraviolet radiation directly induces pigment production by cultured human melanocytes. J Cell Physiol 133: 88-94, 1987

2. Libow LF, Scheide S and Deleo VA: Ultraviolet radiation acts as an independent mitogen for normal human melanocytes in culture. Pigment Cell Res 1: 397-401, 1988.

3. Gilchrest BA, Park H-Y, Eller MS and Yaar M: Mechanisms of ultraviolet light-induced pigmentation. Photochem Photobiol 63: 1-10, 1996.

4. Tomita Y, Hariu A, Kato C and Seiji M: Radical production during tyrosinase reaction, dopa-melanin formation, and photoirradiation of dopa-melanin. J Invest Dermatol 82: 573-576, 1984.

5. Peak JG and Peak MJ: Comparison of initial yields of DNA-toprotein crosslinks and single-strand breaks induced in cultured human cells by far and near-ultraviolet light, blue light and X-rays. Mutat Res 246: 187-191, 1991

6. Wenczl E, Van der Schans GP, Roza L, Kolb RM, Timmerman AJ, Smit NPM, Pavel S and Schothorst AA: (Pheo)Melanin photosensitizes UVA-induced DNA damage in cultured human melanocytes. J Invest Dermatol 111: 678-682, 1998.

7. Karg E, Odh G, Wittbjer A, Rosengren E and Rorsman H: Hydrogen peroxide as an inducer of elevated tyrosinase level in melanoma cells. J Invest Dermatol 100: S209-S213, 1993.

8. Quevedo WC Jr, Holstein TJ, Dyckman J, Mcdonald CJ and Isaacson EL: Inhibition of UVR-induced tanning and immunosuppression by topical applications of vitamin $\mathrm{C}$ and $\mathrm{E}$ to the skin of hairless (hr/hr) mice. Pigment Cell Res 13: 89-98, 2000.

9. Beehler BC, Przybyszewski J, Box HB and Kulesz-Martin MF: Formation of 8-hydroxydeoxyguanosine within DNA of mouse keratinocytes exposed in culture to UVB and $\mathrm{H}_{2} \mathrm{O}_{2}$. Carcinogenesis 13: 2003-2007, 1992.

10. Lee JH, An T, Chung JH, Kim KH, Eun HC and Cho KH: Acute effects of UVB radiation on the proliferation and differentiation of keratinocytes. Photodermatol Photoimmunol Photomed 18: 253-261, 2002.

11. Porter LJ: Flavans and proanthocyanidins. In: The Flavonoids Advances in Research since 1986. Harborne JB (ed). Chapman and Hall, London, pp23-55, 1986.

12. Carando S and Teissedre P-L: Catechin and procyanidin levels in French wines: contribution to dietary intake. In: Plant Polyphenols 2: Chemistry, Biology, Pharmacology, Ecology. Gross GG, Hemingway RW and Yoshida T (eds). Kluwer Academic/Plenum Publishers, New York, pp725-737, 1999.

13. Waterhouse AL and Walzem RL: Nutrition of grape phenolics. In: Flavonoids in Health and Disease. Rice-Evans CA and Packer L (eds). Marcel Dekkar, New York, pp359-385, 1998. 
14. Monagas M, Gómez-Cordovés C, Bartolomé B, Laureano O and Ricardo da Silva JM: Monomeric, oligomeric, and polymeric flavan-3-ol composition of wines and grapes from Vitis vinifera $L$. Cv. Graciano, Tempranillo, and Cabernet Sauvignon. J Agric Food Chem. 51: 6475-6481, 2003.

15. Lau DW and King AJ: Pre- and post-mortem use of grape seed extract in dark poultry meat to inhibit development of thiobarbituric acid reactive substances. J Agric Food Chem 51: 1602-1607, 2003.

16. Yamakoshi J, Saito M, Kataoka S and Tokutake S: Procyanidinrich extract from grape seeds prevents cataract formation in hereditary cataractous (ICR/f) rats. J Agric Food Chem 50: 4983-4988, 2002.

17. Roychowdhury S, Wolf G, Keilhoff G, Bagchi D and Horn T: Protection of primary glial cells by grape seed proanthocyanidin extract against nitrosative/oxidative stress. Nitric Oxide 5: 137-149, 2001

18. Koga T, Moro K, Nakamori K, Yamakoshi J, Hosoyama H, Kataoka S and Ariga T: Increase of antioxidative potential of rat plasma by oral administration of proanthocyanidin-rich extract from grape seeds. J Agric Food Chem 47: 1892-1897, 1999.

19. Bouhamidi R, Prevost V and Nouvelot A: High protection by grape seed proanthocyanidins (GSPC) of polyunsaturated fatty acids against UV-C induced peroxidation. C R Acad Sci III 321: 31-38, 1998.

20. Seo SY, Sharma VK and Sharma N: Mushroom tyrosinase: recent prospects. J Agric Food Chem 51: 2837-2853, 2003.

21. Bagchi D, Bagchi M, Stohs SJ, Das DK, Ray SD, Kuszynski CA, Joshi SS and Pruess HG: Free radicals and grape seed proanthocyanidin extract: importance in human health and disease prevention. Toxicology 148: 187-197, 2000.

22. Shoji T, Masumoto S, Moriichi N, et al: Procyanidin trimers to pentamers fractionated from apple inhibit melanogenesis in B16 mouse melanoma cells. J Agric Food Chem 53: 6105-6111, 2005.

23. Yamakoshi J, Otsuka F, Sano A, Tokutake S, Saito M, Kikuchi M and Kubota Y: Lightening effect on ultraviolet-induced pigmentation of guinea pig skin by oral administration of a proanthocyanidin-rich extract from grape seeds. Pigment Cell Res 16: 629-638, 2003.

24. Abdel-Malek Z, Swope V, Smalara D, Babcock G, Dawes S and Nordlund J: Analysis of the UV-induced melanogenesis and growth arrest of human melanocytes. Pigment Cell Res 7: 326-332, 1994

25. Ando H, Funasaka Y, Oka M, Ohashi A, Furumura M, Matsunaga J, Matsunaga N, Hearing VJ and Ichihashi M: Possible involvement of proteolytic degradation of tyrosinase in the regulatory effect of fatty acids on melanogenesis. J Lipid Res 40: 1312-1316, 1999

26. Lv N, Koo JH, Yoon HY, Yu J, Kim KA, Choi IW, Kwon KB Kwon KS, Kim HU, Park JW and Park BH: Effect of Angelica gigas extract on melanogenesis in B16 melanoma cells. Int J Mol Med 20: 763-767, 2007.

27. Szejda P, Parce JW, Seeds MS and Bass DA: Flow cytometric quantitation of oxidative product formation by polymorphonuclear leukocytes during phagocytosis. J Immunol 133: 3303-3307, 1984.
28. Xiao L, Matsubayashi K and Miwa N: Inhibitory effect of the water-soluble polymer-wrapped derivative of fullerene on UVA-induced melanogenesis via downregulation of tyrosinase expression in human melanocytes and skin tissues. Arch Dermatol Res 299: 245-257, 2007.

29. Yamaguchi F, Yoshimura Y, Nakazawa H and Ariga T: Free radical scavenging activity of grape seed extract and antioxidants by electron spin resonance spectrometry in an H2O2/NaOH/DMSO system. J Agric Food Chem 47: 2544-2548, 1999.

30. Bagchi D, Garg A, Krohn RL, Bagchi M, Bagchi DJ, Balmoori J and Stohs SJ: Protective effects of grape seed proanthocyanidins and selected antioxidants against TPA-induced hepatic and brain lipid peroxidation and DNA fragmentation, and peritoneal macrophage activation in mice. Gen Pharmac 30: 771-776, 1998.

31. Hearing VJ and Tsukamoto K: Enzymatic control of pigmentation in mammals. FASEB J 5: 2902-2909, 1991.

32. Romero-Graillet C, Aberdam E, Biagoli N, Massabni W, Ortonne JP and Ballotti R: Ultraviolet B radiation acts through the nitric oxide and cGMP signal transduction pathway to stimulate melanogenesis in human melanocytes. J Biol Chem 271: 28052-28056, 1996.

33. Romero-Graillet C, Aberdam E, Clement M, Ortonne JP and Ballotti R: Nitric oxide produced by ultraviolet-irradiated keratinocytes stimulates melanogenesis. J Clin Invest 99: 635-642, 1997.

34. Sasaki M, Horikoshi T, Uchiwa H and Miyachi Y: Upregulation of tyrosinase gene by nitric oxide in human melanocytes. Pigment Cell Res 13: 248-252, 2000.

35. Halliwell B: Antioxidant defence mechanisms: from the beginning to the end (of the beginning). Free Radic Res 31: 261-272, 1999.

36. Courdavault S, Baudouin C, Charveron M, Favier A, Cadet J and Douki T: Larger yield of cyclobutane dimers than 8-oxo7,8-dihydroguanine in the DNA of UVA-irradiated human skin cells. Mutat Res 556: 135-142, 2004

37. Barzilai A and Yamamoto K-I: DNA damage responses to oxidative stress. DNA Repair 3: 1109-1115, 2004.

38. Beer JZ, Olvey KM, Miller SA, Thomas DP and Godar DE: Non-nuclear damage and cell lysis are induced by UVA, but not UVB or UVC radiation in three strains of L5178Y cells. Photochem Photobiol 58: 676-681, 1993.

39. Tobi SE, Paul N and McMillan TJ: Glutathione modulates the level of free radicals produced in UVA-irradiated cells. J Photochem Photobiol B 57: 102-112, 2000.

40. Kaufmann WK and Wilson SJ: G1 arrest and cell-cycledependent clastogenesis in UV-irradiated human fibroblasts. Mutat Res 314: 67-76, 1994.

41. Kowalczuk CI, Priestner MC, Pearson AJ, Saunders RD and Bouffler SD: Wavelength dependence of cellular responses in human melanocytes and melanoma cells following exposure to ultraviolet radiation. Int J Radiat Biol 82: 781-792, 2006. 